\title{
IRP04
}

\section{Application of Rate-Transient Analysis for Well} Performance

\author{
T. R. Helail* (National Petroleum Company (NPC) of Jordan) \& A. Khatib \\ (Petrolog \& Associates)
}

\section{SUMMARY}

The most important parts of reservoir engineering in the field-development and production phases are the evaluation of the: original oil or gas in-place (OOIP or OGIP), ultimate oil or gas recoveries, reservoir characteristics and forecasting future production of well/reservoir.

Various techniques for analyzing well performance have been developed and used, including declinecurve analysis, type-curve analysis, pressure-transient analysis (PTA), rate-transient analysis (RTA) and simulation studies.

RTA uses the historical production data for the evaluation of reservoir characteristics and future well performance. It has solid theoretical basis as it uses the pressure transient theory for transient and boundary dominated flow. It overcomes: the shortcomings of the decline analysis which has no theoretical basis and the shortcomings of PTA represented by very short periods of measurement and very limited data over the well history. The long-term nature of the method makes it an important tool for determining reservoir size.

The present paper is concerned with the application of the RTA method for well performance analysis of different types of reservoirs (tight, permeable, oil and gas). The techniques can be used for analyzing Iraqi oil reservoirs, whether the more permeable ones like Rumaila or less permeable reservoirs like the Mishrif. 


\section{Introduction}

The most important parts of reservoir engineering in the field development and production phases are the evaluation of the: original oil or gas in-place (OOIP or OGIP), ultimate oil or gas recoveries, reservoir characteristics and forecasting future production of the total reservoir and individual wells. Various techniques for analyzing well performance have been developed and used. The techniques include decline curve analysis, type-curve analysis, pressure-transient analysis (PTA), rate-transient analysis (RTA) and simulation studies (1\&4).

Of course simulators are the most advanced tools that can perform complicated reservoir studies. Geophysical, geological, petrophysical and dynamic (production) data are incorporated to build a simulation model. This would lead to better reservoir characterization, more reliable results and consequently better development plan for the field.

The main objectives of the decline analysis are: (i) the estimation of reserves and (ii) the prediction of future well/reservoir performance. However, it is an empirical approach with no theoretical basis. Both the decline analysis and Fetkovich type-curve analysis do not consider the effect of flowing pressure. Constant operating conditions are assumed in the decline analysis.

On the other hand, the pressure-transient analysis (PTA) is based on solid theoretical basis, where the diffusivity equation has been solved for various boundary conditions. The main objectives of the analysis are; (i) determination of permeability and skin, (ii) estimation of reservoir pressure and (iii) estimation of drainage area.

Rate-transient analysis (RTA) has solid theoretical bases too, as it uses the pressure- transient theory and the equivalence between the constant rate and constant pressure solutions for transient and boundary-dominated flow. The RTA analysis: (i) covers the objectives of the decline analysis, (ii) covers the objectives of the pressure- transient analysis and (iii) estimates the fluid in place, characterizes the flow regime, analyzes early-time production data and tight gas reservoir data, and may identify some important well problems and reservoir phenomena (6).

\section{RTA Method}

RTA uses the historical production data for the evaluation of reservoir characteristics and future well performance. Usually the production data may have noise, disturbances, or inconsistencies. However, these disadvantages are minimized by the huge amount of data usually available for analysis.

The long-term nature of the method makes it an important tool for determining reservoir size.

Great contributions have been made by L. Mattar and the Fekete Associates Inc. in the development of the techniques and the methodology of its application for analyzing production data. They integrated various modern production-analysis techniques to build software called RTA which is capable of performing all the required analysis on well performance and estimation of original hydrocarbon in place (6). For details on these subjects refer to Fekete Associates Inc. manuals and their related publications (1-6).

The present paper is concerned with the application of the RTA method for well performance analysis of tight or permeable reservoirs, and using different reservoir models for oil and gas reservoirs. The techniques can be used for analyzing Iraqi oil reservoirs, whether the more permeable ones like Rumaila or less permeable reservoirs like the Mishrif.

The production analysis techniques used in the present RTA application include the traditional decline and the modern decline analysis techniques. The full paper includes applications for oil well and gas well from different reservoirs. 


\section{Examples (Optional)}

Various production analysis techniques have been used in the present application, and an example is given for a gas well with production history shown in Fig. 1.

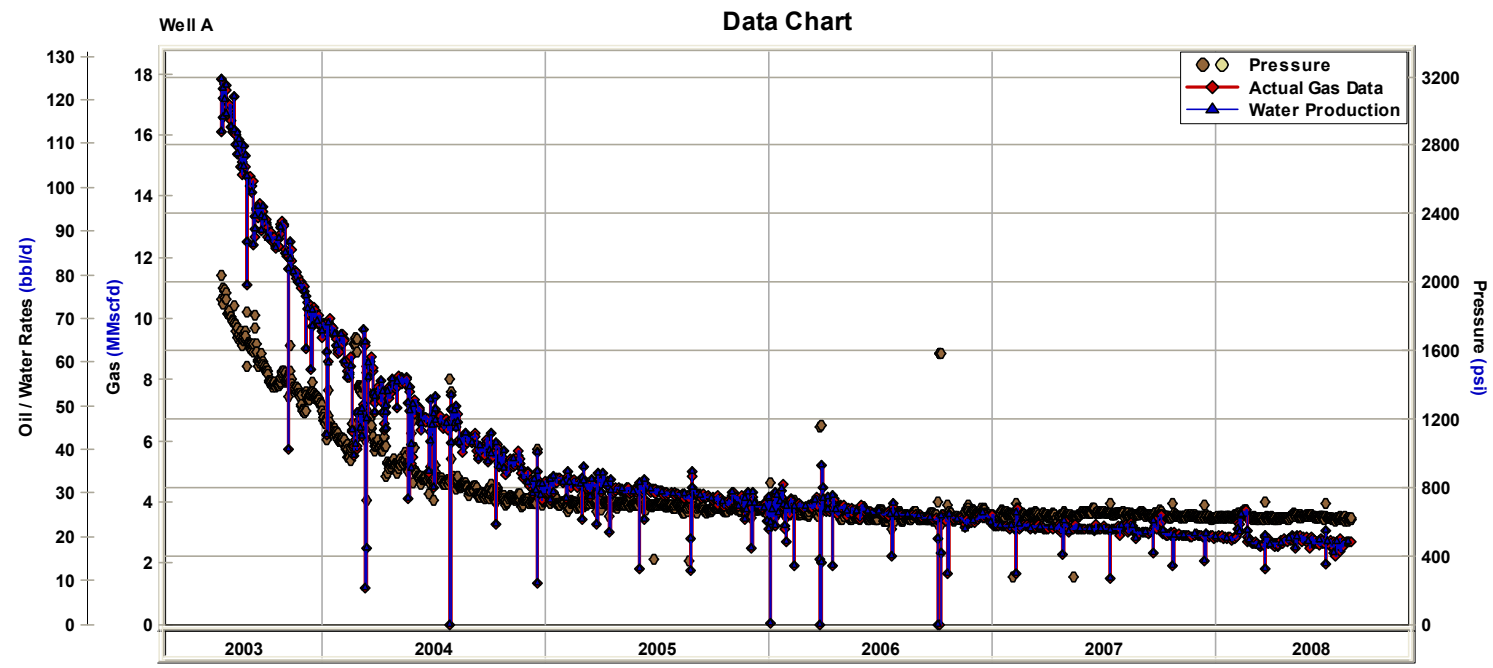

Figure. 1 Production history of a gas well in a tight gas reservoir

The results obtained from the analysis of the flowing material balance (FMB) are presented in Fig. 2.

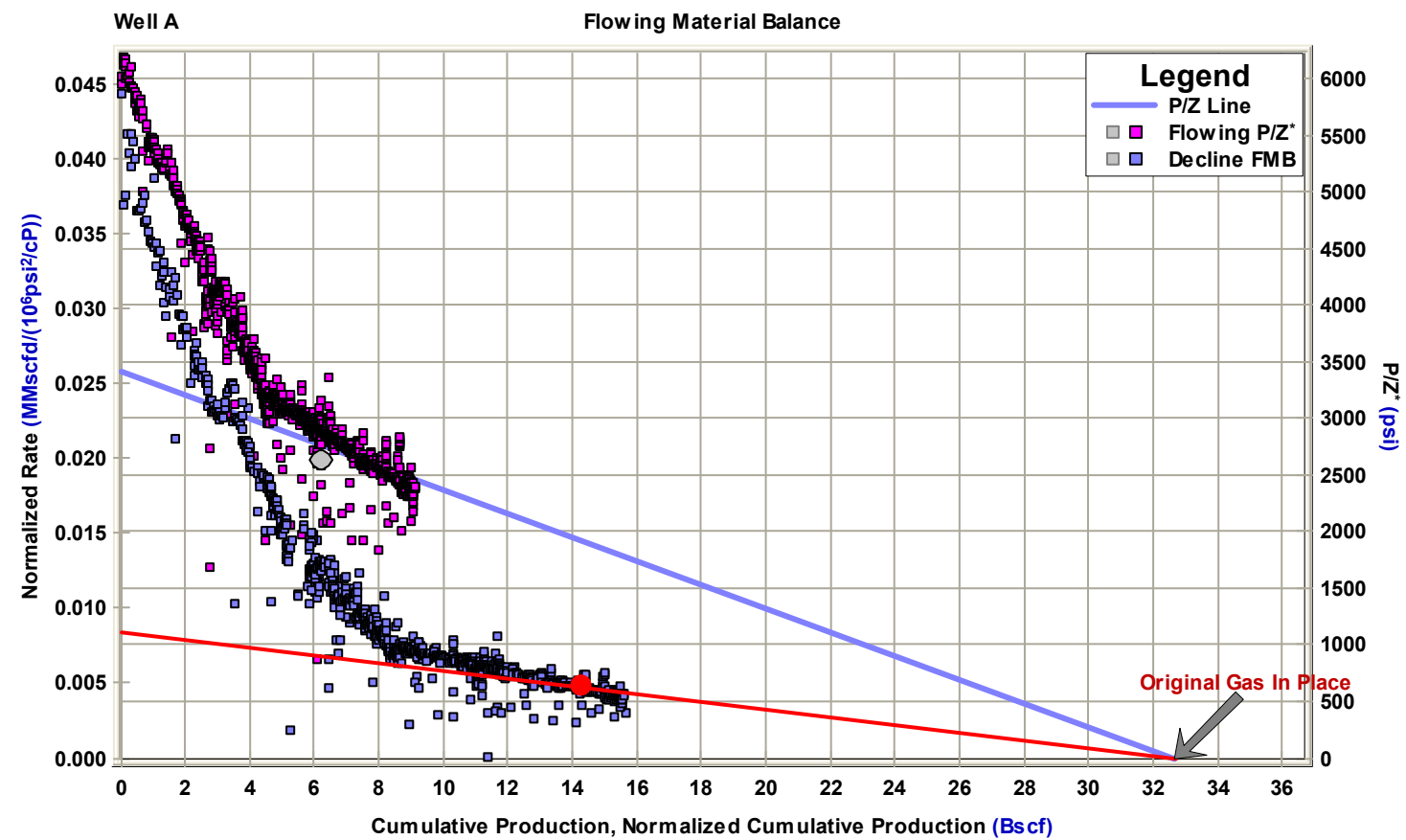

Figure 2 FMB analysis of a gas well in a tight gas reservoir

Fig. 2 clearly shows changing trends from transient flow behaviour to transition period and later to boundary dominated (stabilized) flow. The analysis of the different portions of the plot leads to different values of OOIP or OGIP. Unless stabilization is reached, higher and higher values of OOIP or OGIP are obtained as more production data become available.

The stabilization in tight reservoirs may take very long time (years) to reach and the OOIP or OGIP before this stage represents only the minimum values. 
The full analysis of the data leads to the determination of reservoir properties and other important parameters. These include permeability, skin, fracture half length, flow regime, existence of wellbore problems, etc.

\section{Conclusions}

- RTA is a powerful technique for the evaluation of oil and gas well performance. It is a long- term method which uses the surface measurements of production rate and wellhead pressure over the production history of the well.

- RTA method does not require shutting the well, and the consequent loss of production, as in the PTA method.

- RTA overcomes the shortcomings of the decline analysis which has no theoretical bases and overcomes the shortcomings of PTA represented by very short periods of measurement and very limited data over the well history.

- It has solid theoretical basis as it uses the pressure transient theory and the equivalence between the constant rate and constant pressure solution of the diffusivity equation for transient and boundary-dominated flow.

- The flowing material balance (FMB) provides reliable estimates of fluid-in place and recoverable reserve $(2 \& 3)$. It is a practical alternative to the conventional material balance (CMB) as it uses flowing data thus eliminating: the loss of production, the dependence on sparse BHP data due to high cost involved in the subsurface pressure measurements and the very long time required for pressure stabilization, especially in tight reservoirs. Although both methods require stabilized conditions, the stabilization in FMB occurs while flowing, whereas in CMB it needs to be attained after long shut- in period accompanied with increased loss of production.

- It estimates the contacted drainage area, and thus determines the most likely minimum value of oil or gas initially in place (OOIP or OGIP) and sheds some light on the possibility of reservoir extension.

- RTA can be used for production forecast using various reservoir models.

- RTA analysis may indicate the existence of reservoir pressure support, reservoir interference, water accumulation problems or other kinds of wellbore problems.

\section{References}

Mattar, L. and Anderson, D.M. [2003] A Systematic and Comprehensive Methodology for Advanced Analysis of Production Data., SPE 84472, SPE Annual Technical Conference and Exhibition, October, 2003.

Anderson, D.M. and Mattar, L. [2003] Material-Balance-Time During Linear and Radial Flow. CIPC 201, Canadian International Petroleum Conference, June 2003.

Mattar, L. and McNeil R. [1998] The Flowing Gas Material Balance. Journal of Canadian Petroleum Technology February 1998, 52, 55.

Ilk D., Mattar, L. and Blasingame, T.A.:[2007a] Production Data Analysis-Future Practices for Analysis and Interpretation. CIM 2007-174, 58 $8^{\text {th }}$ Annual Technical Meeting of the Petroleum Society, June 2007.

Ilk D., Rushing, J.A. and Blasingame, T.A. [2008a] Estimating Reserves Using the Arps Hyperbolic Rate-Time Relation - Theory, Practice and Pitfalls. CIM 2008-108, 59 ${ }^{\text {th }}$ Annual Technical Meeting of the Petroleum Society, June 2008.

RTA Manual Fekete Associates Inc. 